\title{
Etil Alkol Yakıtlı HCCI Motorun Performans, Yanma ve Emisyon Özeliklerinin Deneysel Olarak İncelenmesi
}

\author{
Alper CALAM $^{1} \odot$, Serdar HALİ ${ }^{2 *}$ \\ ${ }^{1}$ Gazi Üniversitesi, Teknik Bilimler MYO, Makine ve Metal Teknolojileri Bölümü, Ankara, Türkiye \\ ${ }^{2}$ Gazi Üniversitesi, Teknoloji Fakültesi, Otomotiv Mühendisliği Bölümü, Ankara, Türkiye \\ Geliş / Received: 21/08/2019, Kabul / Accepted: 20/02/2020
}

\begin{abstract}
$\ddot{O} z$
$\mathrm{Bu}$ çalışmada dört zamanlı, tek silindirli, port enjeksiyonlu bir benzinli motordan (SI) homojen dolgulu sıkıştırma ile ateşlemeli motora (HCCI) dönüşümü yapılmış Ricardo Hydra test motoru kullanılmıştır. Referans heptan ve heptan/etil alkol karışımlarının (E15 ve E25) yanma, motor performansı ve egzoz emisyonlarına etkisi deneysel olarak incelenmiştir. Emme havası giriş sıcaklığ $60^{\circ} \mathrm{C}$ 'de sabitlenmiş ve motor hızı $800 \mathrm{rpm}$ olarak belirlenmiştir. Farklı hava fazlalık katsayısı (HFK) değerlerinde silindir içi basınç, 1sı dağılımı, yanma başlangıcı, CA50, yanma süresi, indike termik verim, indike ortalama efektif basınç (IMEP) ve egzoz emisyon sonuçları incelenmiştir. Heptan yakıtına etil alkol ilavesi yanmanın gecikmeye alınarak uzamasına neden olmuştur. Ayrıca yanmanın yavaşlatılması sağlanmıştır. Buna bağlı olarak basınç artış oranı azalarak HCCI yanma kontrol altına alınmıştır. En yüksek indike termik verim E15 yakıtı kullanımında HFK'nın 2 olduğu şartlarda \%49 olarak belirlenmiştir. En yüksek IMEP E25 yakıtı kullanımında HFK'nın 1,3 olduğu şartlarda 6,1 bar olarak tespit edilmiştir. $\mathrm{CO}$ ve $\mathrm{HC}$ emisyonları ise heptan yakıtına etil alkol ilave edilmesi ile eş zamanlı olarak artı̧̧ göstermiştir. Karışım yakıtları kullanımında silindir içi gaz sıcaklıklarının heptana göre düşük olması, yüksek emisyon değerlerinin temel nedeni olduğu ifade edilebilir. E15 yakıtının uygun çalışma şartlardında ideal yakıt olduğu bu çalışma ile ifade edilebilir.
\end{abstract}

Anahtar Kelimeler: Düşük sıcaklık yanması, HCCI, Performans, Etil alkol, Yakıt, Emisyon.

\section{Experimental Investigations of Performance, Combustion and Emission Characteristics of Ethanol Fueled HCCI Engine}

\begin{abstract}
In this study, Ricardo Hydra test engine which has been converted from a four stroke, single cylinder, port injection spark ignition (SI) engine to homogeneous charged compression ignition (HCCI) engine was used. The effect of reference heptane and heptane / ethyl alcohol mixtures (E15 and E25) on combustion, engine performance and exhaust emissions was investigated experimentally. The intake air inlet temperature is fixed at $60^{\circ} \mathrm{C}$ and the engine speed is determined as $800 \mathrm{rpm}$. In-cylinder pressure, heat release, start of combustion, CA50, combustion duration, indicated thermal efficiency, indicated mean effective pressure (IMEP) and exhaust emission results were investigated at different lambda values. Addition of ethyl alcohol to heptane resulted in delayed and prolonged combustion. Also this provided to slowing of the combustion. Consequently, the pressure rise rate decreased and HCCI combustion was controlled. The highest indicated thermal efficiency was found to be $49 \%$ when the lambda value was 2 and use of E15 fuel. The highest IMEP was found to be 6,1 bar when the lambda value was 1,3 and use of E25 fuel. CO and HC emissions increased simultaneously with the addition of ethyl alcohol to the heptane fuel. Compared to heptane, when the E15 and E25 fuels are used, it can be stated that the low in-cylinder gas temperatures are the main reason for the high emission values. It can be stated that E15 fuel is the ideal fuel under suitable operating conditions via this study.
\end{abstract}

Keywords: Low temperature combustion, HCCI, Performance, Ethanol, Fuel, Emission. 


\section{Giriş}

Dünyayı ciddi olarak etkileyen enerji sorunu ve çevre kirliliği dikkate alındığında konvansiyonel içten yanmalı motorlardaki alternatif yakıtların kullanılabildiği ileri yanma stratejileri daha iyi yakıt ekonomisi ve düşük egzoz emisyonu gibi avantajlar sunmaktadır. $\mathrm{Bu}$ nedenle yüksek termik verime sahip olan, çok düşük azot oksit $\left(\mathrm{NO}_{\mathrm{x}}\right)$ ve is emisyonu (PM) üreten yeni bir yanma modeli olan homojen dolgulu sıkıştırma ile ateşlemeli (HCCI) motorlar gelecek vaad etmektedir (Zhang vd., 2016; Kozlov vd., 2018; Blomberg vd., 2018).

Buji ile ateşlemeli (SI) ve dizel motorların (DI) avantajlarını bir arada bulunduran HCCI yanma modelinde, fakir hava yakit karışımının yanması silindir içi gazların sıcaklığının düşük olmasına neden olmaktadır. Buna bağlı olarak $\mathrm{NO}_{\mathrm{x}}$ ve is emisyonları azalmaktadır. Ayrıca HCCI motorlarda gaz kelebeği kısılma kayıpları olmaması nedeniyle termik verim artış göstermektedir. HCCI motorların bu avantajlarının yanı sira yanmanın kontrol edilebilmesinin zorluğu ve çalışma aralığının oldukça dar olması gibi çeşitli sorunları bulunmaktadır (Zhang vd., 2012; Zhao vd., 2003). Ayrıca fakir karışım yanma sonu gaz sıcaklıklarının düşük olmasına neden olmakta ve bu durum karbon monoksit (CO) ve hidrokarbon (HC) emisyonlarını kötüleştirmektedir. Çünkü CO emisyonları yanma sonu sıcaklıklarından güçlü bir şekilde etkilenmektedir (Curran vd., 1998; Cinar vd., 2015). HCCI motorlarda SI motorlarda olduğu gibi yanmayı kontrol eden buji ya da

\footnotetext{
*Sorumlu Yazar: serdarhalis@ gazi.edu.tr
}

dizel motorlarda olduğu gibi doğrudan yanmayı kontrol eden direkt enjeksiyon sistemi bulunmamaktadır. HCCI motorlarda yanma başlangıcı, sıkıştırma zamanı sonunda hava yakıt karışımının kimyasal kinetikleri tarafından kontrol edilmektedir (Shudo vd., 2009; Yao vd., 2009; Noh vd., 2017). Yak1t özellikleri, hava yakıt karışım konsantrasyonu, silindir içi basınç ve sıcaklık HCCI yanmayı etkilemektedir. Bu nedenle HCCI motorlarda kullanılan yakitların özellikleri, emme havası giriş sıcaklığı ve basıncı yanma için oldukça önemlidir (Polat, 2016; Uyumaz, 2015). Ayrica yanmanın yavaşlatılarak kontrol altına alınabilmesi için egzoz gazı geri dönüşümü (EGR) ve değişken supap zamanlaması gibi yöntemler de kullanılmaktadır (Saisisirat vd., 2011).

HCCI motorlarda dizel tipi yakitların kullanımında benzine göre kendiliğinden tutuşma sıcaklıklarının düşük olması nedeniyle yanma kolay bir şekilde sağlanabilmektedir. Ancak dizel yakıtlarının zor buharlaşması ve volalitesinin düşük olması nedeniyle hava ile iyi bir karışım sağlamak zordur. N-heptan, oktan sayısının belirlenmesinde referans yakıt (PRF) olarak kullanılmaktadır ve setan sayısı 56'dır. Bu özelliği sayesinde geleneksel dizel yakıtına benzemektedir. Bu nedenle birçok çalışmada n-heptan, dizel yakıtlarının HCCI yanmasında vuruntu ve kendiliğinden tutuşma karakteristiklerinin belirlenmesinde kullanılmaktadir (Zheng vd., 2004; Peng vd., 2003; Huang vd., 2005). Geçmiş çalışmalar göstermiştir ki n-heptan yakıtı ile HCCI motorlar kolay bir şekilde çalıştırılabilmektedir. Ancak n-heptan yakıtı 
kendi kendine çok kolay tutuşmaktadır. $\mathrm{Bu}$ nedenle yanma aşırı avansa alınmaktadır. Erken ateşlemenin fazla olması ve zengin karışım şartlarında vuruntulu çalışma, nheptan yakıtı kullanımında HCCI motorların çalışma aralığının oldukça daralmasına neden olmaktadır. N-heptan yakıtı çalışma aralığının genişletilebilmesi için yüksek oktan sayısına sahip yakıtlar ile karışım halinde kullanılabilmektedir (Ogawa vd., 2003).

Yüksek oktan sayısına sahip olduğu bilinen metil alkol ve etil alkol geleneksel SI motorlarda vuruntuyu önlemesi amaciyla yakıt katk1 maddesi olarak kullanılmaktadır. Alkol bazlı yakıtlar kendiliğinden tutuşmayı engelleyerek yanmanın gecikmeye alınmasını sağlamaktadır (Lü vd., 2006). Etil alkol, içeriğinde şeker bulunan birçok bitkisel üründen üretilebilmektedir. Şeker kamışı ve dolayısı ile etil alkol üretiminin fazla olduğu Brezilya'da yakıt olarak ya da ABD ve Kanada gibi ülkelerde oktan sayısı geliştirici yakıt katkı maddesi olarak kullanılmaktadır (Poulopoulos vd., 2001). HCCI yanmasinda etil alkolün yakıt olarak kullanımı 1s1 yayılımının yavaşlamasına neden olmaktadır. Ayrıca alkollerin içeriğinde oksijen bulunması yanma sonu kirletici emisyonların azaltılmasını sağlamaktadır (Shibata vd., 2005; Maurya vd., 2014).

Etil alkol ve metil alkolün HCCI motorlarda yakıt olarak kullanımı ile ilgili bazı çalışmalar yapılmıştır. Christensen ve ark. (Christensen vd., 1997), etil alkolün HCCI motorlarda kullanımı ile ilgili ilk çalışmayı gerçekleştirmiştir. Sonuçlar göstermiştir ki HCCI modda etil alkolün yakıt olarak kullanılması SI moda göre $\mathrm{NO}_{x}$ emisyonlarının azaltılmasını sağlamıştır. Ancak HCCI modda yanma sonu sıcaklıklarının düşük olması nedeniyle $\mathrm{CO}$ ve HC emisyonları artış göstermiştir. Etil alkolün yakıt olarak kullanımında maksimum silindir içi basınç HCCI modda elde edilmiştir. Tongroon ve ark. (Tongroon vd., 2010), etil alkol, metil alkol ve benzinin HCCI yanması üzerine etkilerini incelemişlerdir. En hızlı ve en erken metil alkol kendi kendine ateşlenirken, ardından etil alkolün hızlı bir şekilde yandığını rapor etmişlerdir. Benzin kullanımında ise en yavaş yanma gerçekleşmiştir. Oakley ve ark. (Oakley vd., 2001), etil alkol ve metil alkolün benzine göre daha geniş bir çalışma aralığına sahip olduğunu ifade etmişlerdir. Xie ve ark. (Xie vd., 2006) ile Li ve ark. (Li vd., 2008), alkollerin kendiliğinden daha erken krank açılarında tutuştuğunu ve egzoz emisyonlarını azaltıcı bir etki gösterdiğini belirtmişlerdir.

Bu çalışmanın temel amacı, n-heptan yakıtına etil alkol ilavesinin HCCI yanması üzerine etkilerinin incelenmesidir. N-heptan yakıtının referans yakıt olarak " 0 " oktan sayısına sahip olması yanmanın erken krank açılarında başlamasına ve 1sı yayılımının hızlı olmasına neden olmaktadır. Hizlı 1sı yayılımı vuruntu problemini ortaya çıkarmaktadır. $\mathrm{Bu}$ çalışmada n-heptan yakıtına etil alkol ilave edilerek HCCI yanmasının kontrol altına alınması amaçlanmaktadır. Bunun için \%15 etil alkol-\%85 heptan (E15), \%25 etil alkol $\% 75$ heptan (E25) yakıtları deney yakıt1 olarak belirlenmiştir. N-heptan içerisindeki etil alkol miktarının artması ile silindir içi basınç, 1sı yayılımı, yanma başlangıcı, yanma süresi, termik verim, HCCI çalışma aralığ 1 ve egzoz emisyonlarına etkileri detaylı bir şekilde incelenerek karşılaştırmalı analiz yapilmıştır.

\section{Materyal ve Metot}

Çalışma; dört zamanlı, tek silindirli, su ile soğutmalı, port enjeksiyonlu bir buji ile ateşlemeli motordan dönüşümü gerçekleştirilmiş bir HCCI motorda 
yapılmıştır. Yakıt sistemi, enjektörün açık kalma süresinin değiştirilebildiği bir ara yüz program ile kumanda edilmiştir. Deney motorunun teknik özellikleri Tablo 1'de, deney düzeneğinin şematik görünümü ise Şekil 1'de görülmektedir.

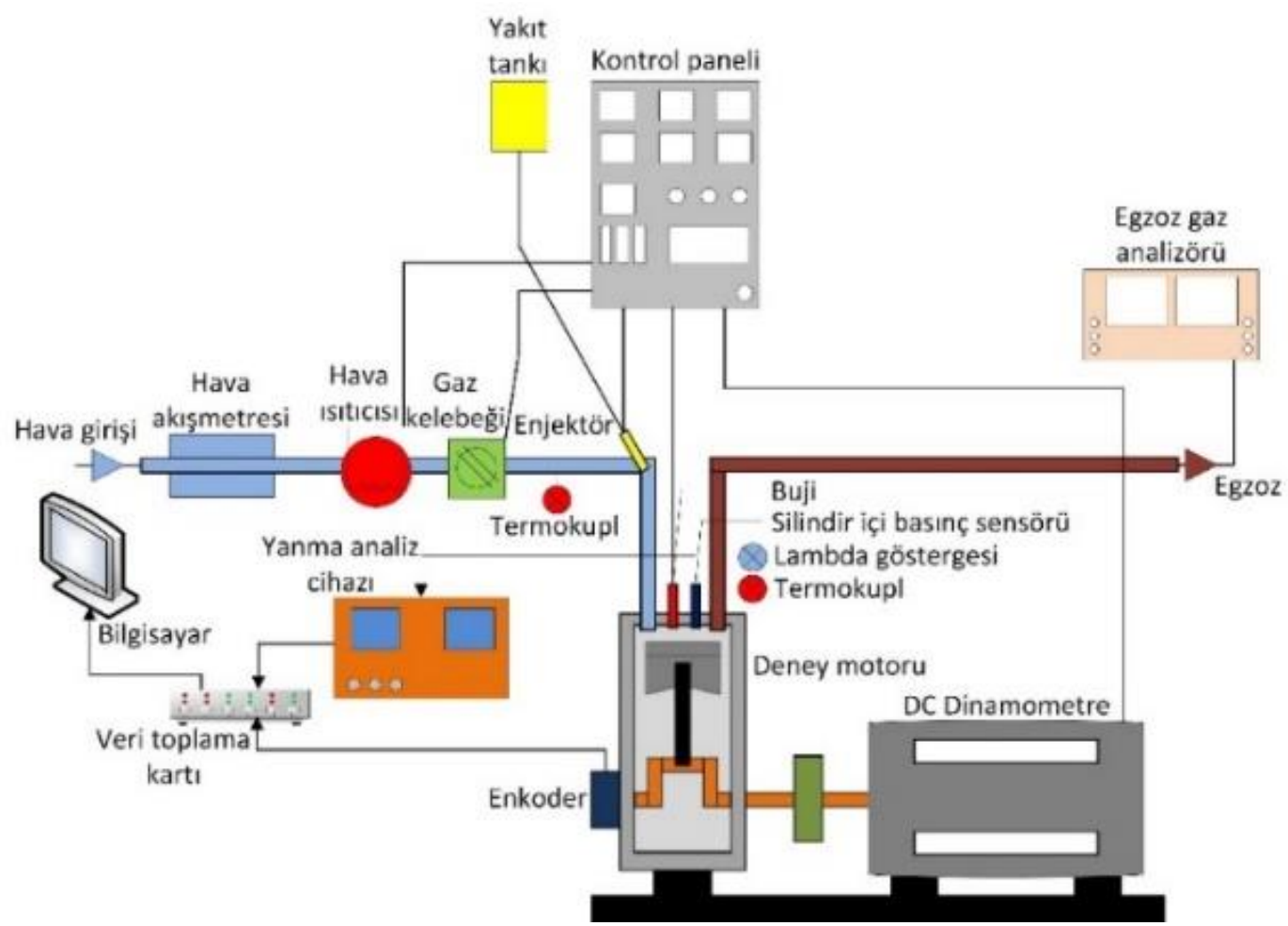

Şekil 1. Deney düzeneğinin şematik görünümü

Tablo 1. Deney motorunun teknik özellikleri

\begin{tabular}{|c|c|}
\hline Markası & Ricardo Hydra \\
\hline Silindir say1s1 & 1 \\
\hline Çap (mm) X Kurs (mm) & $80,26 \times 88,90$ \\
\hline S1kıştırma Oranı & $13: 1$ \\
\hline Supap sistemi & $\begin{array}{l}\text { Üstten kamlı düşey iki } \\
\text { supap }\end{array}$ \\
\hline Yak1t sistemi & Port tipi enjeksiyon \\
\hline $\begin{array}{l}\text { Emme supabı açılma } \\
\text { zamanlaması }\end{array}$ & ÜÖN'dan $12^{\circ} \mathrm{KA}$ önce \\
\hline $\begin{array}{l}\text { Emme supab1 kapanma } \\
\text { zamanlamas1 }\end{array}$ & AÖN'dan $56^{\circ} \mathrm{KA}$ sonra \\
\hline $\begin{array}{l}\text { Egzoz supabı açılma } \\
\text { zamanlaması }\end{array}$ & AÖN'dan $56^{\circ} \mathrm{KA}$ önce \\
\hline $\begin{array}{l}\text { Egzoz supabi kapanma } \\
\text { zamanlamas1 }\end{array}$ & ÜÖN'dan $12^{\circ}$ sonra \\
\hline $\begin{array}{l}\text { Supap kalkma miktarı } \\
(\mathrm{mm})\end{array}$ & $\begin{array}{l}\text { Emme } \\
3,5 \mathrm{~mm}\end{array} \quad 5,5 \mathrm{~mm}$, \\
\hline
\end{tabular}

Deneyler esnasında HCCI yanmayı sağlayabilmek için port enjeksiyon sistemi kullanılmıştır. Yakıt miktarı, port enjektörün püskürtme karakteristiğinin belirlendiği yakıt kontrol sistemi tarafından kumanda edilmiştir. Enjektörün açık kalma süresi kontrol panelinde ayarlanarak sabit tutulmuştur. Böylece deneyler esnasında hava/yakıt oranı sabit tutulmuştur. Farklı enjeksiyon süreleri belirlenerek etil alkol/n-heptan yakıt karışımlarının farklı hava fazlalık katsayısı (HFK) değerlerinde HCCI yanmaya etkisi incelenmiştir. Deneyler esnasında yakıt tüketiminin belirlenebilmesi adına her yakıt için enjeksiyon karakteristiği belirlenmiştir. Yakıt haznesi 0,01 g hassasiyetine sahip bir terazi üzerine yerleştirilmiş ve 120 saniye boyunca enjektörün farklı açık kalma sürelerinde kütlesel olarak ne kadar yakıt püskürttüğü belirlenmiştir. Buna bağlı olarak doğru denklemi belirlenmiş ve çalışma boyunca enjektör açık kalma süresine bağlı olarak yakıt tüketim değerleri elde edilmiştir. 
Deney motoru 6500 rpm'de $30 \mathrm{~kW}$ güç absorbe edebilen McClure marka elektrikli tip dinamometreye bağlanmıştır. Emme havası 1sitıcıs1, emme manifoldunun motor bloğuna bağlandığı noktanın hemen önünde bulunmaktadır. Emme havası giriş sıcaklığı, 1sitma sisteminin hemen arkasinda yer alan $\mathrm{K}$ tipi termokupl kullanılarak ölçülmüş ve sıcaklık kapalı devre denetleyicisi ile sabit tutulmuştur. Silindir içi basıncın ölçümü için Kistler 6121 piezoelektrik basınç sensörü kullanılmıştır. Tablo 2' de basınç sensörünün teknik özellikleri görülmektedir.

Tablo 2. Silindir içi basınç sensörü teknik özellikleri

\begin{tabular}{ll}
\hline Marka / model & $\begin{array}{l}\text { Kistler 6121 } \\
\text { piezoelektrik }\end{array}$ \\
\hline Çalışma aralığ1 (bar) & $0-250$ \\
Ölçüm hassasiyeti $(\mathrm{pC} / \mathrm{bar})$ & 14,7 \\
Çalışma sıcaklığ1 $\left({ }^{\circ} \mathrm{C}\right)$ & $-50-350$ \\
Ölçüm toleransı $(+/-\%)$ & 0,5 \\
\hline
\end{tabular}

Silindir içi ham basınç sinyalleri Cussons P4110 yanma analiz cihazı ile toplanmış ve yükseltilmiştir. Alınan analog silindir içi basınç sinyalleri National Instruments marka USB 6259 model veri toplama kartında dijital sinyallere dönüştürülmüştür. Pistonun silindir içindeki konumunu belirlemek için krank mili üzerine bir enkoder bağlanmıştır. Enkoder her $0,36^{\circ}$ krank açısında (KA) sinyal üretmektedir. Dolayısı ile bir çevrim için 2000 adet veri kaydedilmektedir. Dönüştürülen silindir içi basınç sinyalleri ve pistonun pozisyonu eş zamanlı olarak bilgisayara kaydedilmiştir. Her bir deney şartı için ardışık 50 çevrim boyunca elde edilen verilerin ortalaması alınmıştır.

Deneysel çalışmalara başlamadan önce deney motoru SI yanma modunda çalıştırılmıştır. Yağlama yağı sıcaklığı kontrol edilerek çalışma sıcaklığına ulaşıldığında $\left(65^{\circ} \mathrm{C}\right)$ port enjeksiyon sistemi üzerinden yakit püskürtülmüş ve SI yakıt sistemi kapatılarak HCCI yanma sağlanmıştır. Çalışma boyunca yağlama yağı sıcaklığı kontrol edilerek sabit tutulmuştur.

Deneyler 800 rpm motor hızında, farklı HFK değerlerinde gerçekleştirilmiştir. Deneylerde saflık derecesi \%99 olan Sigma Aldrich marka n-heptan ve \%99,5 saflikta etil alkol kullanılmıştır. N-heptan yakıtına hacimsel olarak $\% 15$ ve $\% 25$ oranlarında etil alkol ilave edilerek deney yakıtları elde edilmiştir. Deney sonuçları referans n-heptan yakıtı ile karşılaştırmalı olarak incelenmiştir. Deney yakıtlarının teknik özellikleri Tablo 3 'te görülmektedir.

Tablo 3. N-heptan ve etil alkol yakıtlarının özellikleri

\begin{tabular}{lcc}
\hline & n-Heptan & Etil Alkol \\
\hline RON & 0 & $110-115$ \\
Kimyasal formül & $\mathrm{C}_{7} \mathrm{H}_{16}$ & $\mathrm{C}_{2} \mathrm{H}_{5} \mathrm{OH}$ \\
Yoğunluğu $\left(\mathrm{kg} / \mathrm{m}^{3}\right.$ at & 695 & 788 \\
$\left.15,4^{\circ} \mathrm{C}\right)$ & & \\
Kaynama noktasi $(\mathrm{K})$ & 371 & 78,37 \\
Alt 1s1l değeri $(\mathrm{kJ} / \mathrm{kg})$ & 44566 & 27860 \\
\hline
\end{tabular}

Egzoz gazlarının analizi için Bosch BEA350 marka emisyon ölçüm cihazı kullanılmıştır. Egzoz gazı analiz cihazı $\mathrm{HC}, \mathrm{CO}, \mathrm{O}_{2}, \mathrm{CO}_{2}$ ve NO emisyonlarını ölçebilmektedir. Bununla birlikte emisyon cihazı lambdayı Brettschneider formülünü kullanarak hesaplayabilmektedir. Deneylerde kullanılan egzoz gazı analiz cihazının teknik özellikleri Tablo 4' te görülmektedir.

Tablo 4. Egzoz gaz analizörü teknik özellikleri

\begin{tabular}{lcc}
\hline & Ölçme aralığ & Hassasiyet \\
\hline $\mathrm{CO}(\%$ vol.) & $0-10$ & 0,001 \\
$\mathrm{HC}(\mathrm{ppm})$ & $0-9999$ & 1 \\
$\mathrm{NO}(\mathrm{ppm})$ & $0-5000$ & 1 \\
$\mathrm{CO}_{2}(\%$ vol.) & $0-18$ & 0,01 \\
$\mathrm{O}_{2}(\%$ vol.) & $0-22$ & 0,01 \\
Lambda & $0,5-9,999$ & 0,001 \\
\hline
\end{tabular}

Silindir içi basınç, ardışık 50 çevrim boyunca elde edilen verilerin ortalaması alınarak hesaplanmıştır. Çevrim başına 2000 veri kaydedilirken 50 çevrimde toplam 100000 verinin ortalaması alınmıştır. Bunun için MATLAB programlama kodu kullanılarak bir 
algoritma hazırlanmıştır. Yapılan termodinamik analiz ile silindir içi basınç, 1sı dağılımı, yanma başlangıcı (CA10), yanmanın sona erdiği krank açısı (CA90), yanma süresi (CA10-90), kümülatif 1s1 dağılımının \%50'sinin gerçekleştiği krank açısı (CA50), indike ortalama efektif basınç (IMEP) ve termik verim hesaplanmıştır. Isı dağılımının belirlenebilmesi için termodinamiğin birinci yasasından faydalanılmıştır. $\mathrm{Bu}$ nedenle bir çevrim boyunca kütle ve gaz kaçakları ihmal edilmiştir. Silindirden silindir duvarına gerçekleşen 1s1 transferi, 1S1 yayılım oranını belirlemek için hesaplanmıştır. Krank açısına bağlı olarak 1sı yayılım oranı Eş. 1 ile hesaplanmıştır.

$$
\frac{d Q}{d \theta}=\frac{k}{k-1} P \frac{d V}{d \theta}+\frac{1}{k-1} V \frac{d P}{d \theta}+\frac{d Q_{u s l}}{d \theta}
$$

Burada $d Q$ net 1 sı çıkışıdır, $P$ ve $V$ sırası ile silindir basıncı ve silindir hacmidir. $d \theta$ krank açısının değişimi ve $k$ özgül 1sıların oranını ifade etmektedir. $\frac{d Q_{s l}}{d \theta}$ ise silindir duvarına gerçekleşen 1s1 transferini ifade etmektedir.

Termik verim Eş. 2 ile hesaplanmıştır.

$$
\eta_{T}=\frac{W_{n e t}}{\dot{m}_{\text {etilalkol }} \times Q_{L H V \text { etilaklol }}+\dot{m}_{n-\text { hep tan }} \times Q_{L H V n \text {-hep tan }}}
$$

burada, $W_{n e t}$ net işi, $\dot{m}_{\text {etilalkol }}$ ve $\dot{m}_{n-h e p \text { tan }}$ etil alkol ve n-heptanın çevrim başına yakıt tüketimini, $Q_{L H V \text { etilalkol }}$ ve $Q_{L H V \text {-heptan }}$ ise etil alkol ve n-heptan yakıtlarının alt 1sıl değerlerini ifade etmektedir.

Net iş Eş. 3 ile hesaplanmıştır.

$$
W_{n e t}=\int P d V
$$

IMEP değerleri, silindir sayısına, silindir hacmine ve motor hızına bağlı olmadığından, motor performansının belirlenmesinde temel bir parametre olarak kullanılabilmektedir. IMEP işin kurs hacmine bölünmesi ile elde edilmektedir. IMEP Eş. 4'te görüldüğü gibi hesaplanmaktadır. Burada $V_{\text {kurs }}$ kurs hacmini ifade etmektedir.

$$
\text { imep }=\frac{W_{\text {net }}}{V_{\text {kurs }}}
$$

\section{Bulgular}

HCCI motorlarda motor yükü hava yakıt oranının değişimi ile kontrol edilmektedir (Zhao, 2007). Şekil 2 (a-b-c)'de heptan, E15 ve E25 yakıtları kullanımında HFK'ya bağlı olarak silindir içi basınç ve 1s1 dağglımının değişimi görülmektedir. Heptan yakıtı kullanımında HFK'nın 1,55 ile 2,6 aralığında HCCI yanma sağlanmıştır. HFK'nın 1,55 olduğu şartlar vuruntu sınırını ifade ederken 2,6 olduğu şartlar ise tekleme sınırını göstermektedir. Heptan için en yüksek 1S1 dağılımı ve silindir içi basınç, en zengin karışım olan HFK'nın 1,55 olduğu şartlarda gerçekleşmiştir. Karışımın zenginleşmesi ile silindir içerisine sürülen enerji miktarı da artış göstermektedir. Ayrıca heptan yakıtı kullanımında ve tüm HFK değerlerinde 1s1 dağılımının büyük bir kısmının ÜÖN'dan önce gerçekleştiği Şekil 2 (a)'da görülmektedir. Şekil 2 (b)'de E15 yakıtına ait silindir içi basınç ve 1sı dağılımının farklı HFK değerlerindeki değişimi görülmektedir. E15 yakıtı kullanımında HFK'nın 1,4 ile 2,5 aralığında HCCI yanma sağlanmıştır. E25 yakıtı kullanımında ise HFK'nın 1,3 ile 2,4 şartları arasında (Şekil 2 (c)) HCCI yanma sağlanmıştır. Etil alkolün oktan sayısı ve buharlaşma gizli ısısı n-heptandan yüksektir (Li vd., 2018). Bu nedenle karışım 
yakıtlarındaki etil alkol miktarı artış gösterdikçe, silindir içi kimyasal reaksiyonlar yavaşlamakta ve çalışma aralığ 1 zengin karışım şartlarına doğru kaymaktadır. Ayrıca Şekil 2 a, b ve c beraber incelendiğinde 1s1 dağılımının ve maksimum silindir içi basıncın
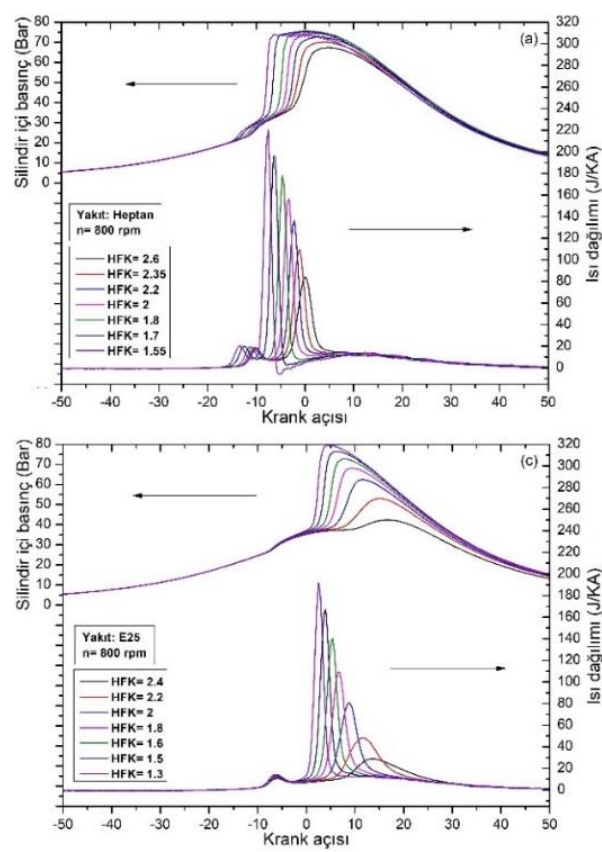

Şekil 2. HFK'ya bağlı silindir içi basınç ve 1sı dağılımının değişimi

Heptan yakıtına etil alkol ilavesi ile elde edilen karışım yakıtlarının alt 1sıl değeri azalmaktadır (Tablo 3). Buna bağlı olarak aynı HFK değerinde silindir içine sürülen enerji miktarı da azalmaktadır. Böylece heptan yakıtına göre E15 ve E25 yakıtının açığa çıkardığı 1 sı enerjisi de düşük olmaktadır. Bununla birlikte özellikle E25 yakıtı kullanımında 1sı dağılımının büyük bir kısmının genişleme zamanına kayması, silindir içi basıncın diğer yakıtlara göre çok düşük elde edilmesine neden olmuştur.

İçten yanmalı motorlarda kümülatif 1s1 dağılımının \%10’unun gerçekleştiği krank açısı yanma başlangıcı olarak ifade edilmektedir (Heywood, 1988). Şekil 3'te heptan, E15 ve E25 yakitlarının yanma başlangıcının HFK'ya bağlı değişimi görülmektedir. Heptan yakıtı kullanımında tüm HFK değerlerinde yanma ÜÖN'dan önce
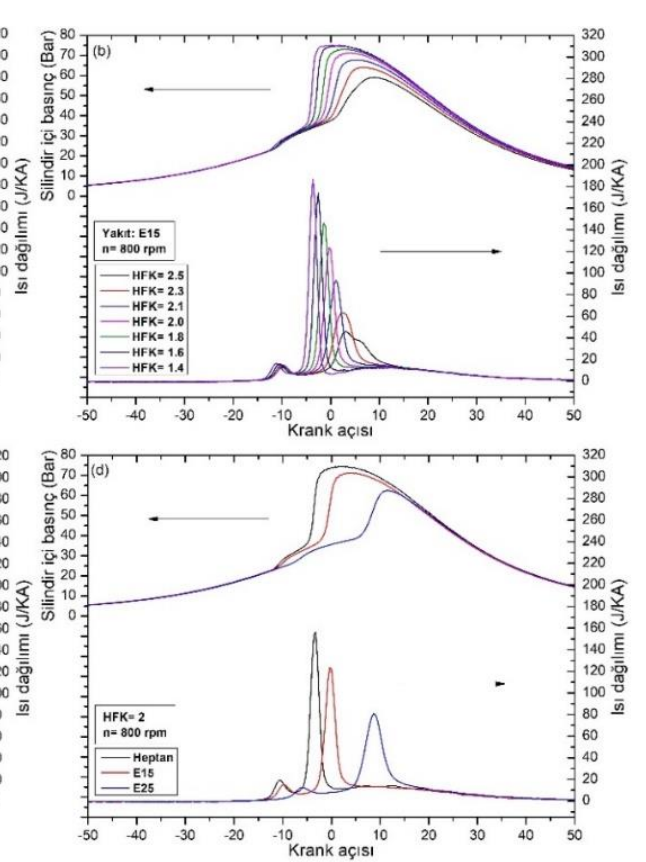

oluşma şartları gecikmeye alınmaktadır. Bunun temel nedeni silindir içi reaksiyon hızının yavaşlaması ve yanmanın daha uzun krank açılarında tamamlanmasıdır. Şekil 2 (d)'de HFK'nın 2 olduğu şartlarda üç deney yakıtı karşılaştırmalı olarak incelenmiştir.

başlarken, E25 yakıtı kullanımında ise tüm HFK değerlerinde yanma ÜÖN'dan sonra başlamıştır. HCCI yanması silindir içi kimyasal kinetiklere oldukça bağlıdır. Ayrıca silindir içi sıcaklık geçmişinden de büyük ölçüde etkilenmektedir. Heptan yakıtının etil alkole göre yüksek reaktivite özelliği yanmanın daha erken krank açılarında başlamasını sağlamıştır. Etil alkolün zor buharlaşması ise E15 ve E25 karışım yakıtlarının yanma başlangıcını gecikmeye almaktadır. Zor buharlaşan etil alkol, ortamdan daha fazla 1sı enerjisi çekmekte ve yanma sonu sicaklıklarının azalmasına neden olmaktadır. Düşük silindir içi gaz sıcaklığı silindir içi reaksiyon hızını azaltmakta ve yanma gecikmeye alınarak yavaşlamaktadır. Ayrıca tüm test yakıtları kullanımında HFK'nın artışı ile yanmanın ilave olarak gecikmeye alındığı görülmektedir. 


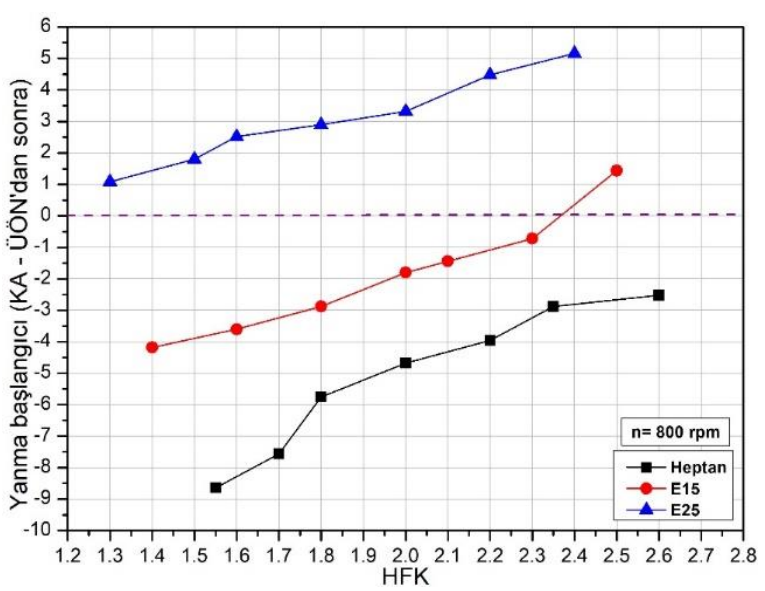

Şekil 3. Yanma başlangıcının HFK’ya bağlı değişimi
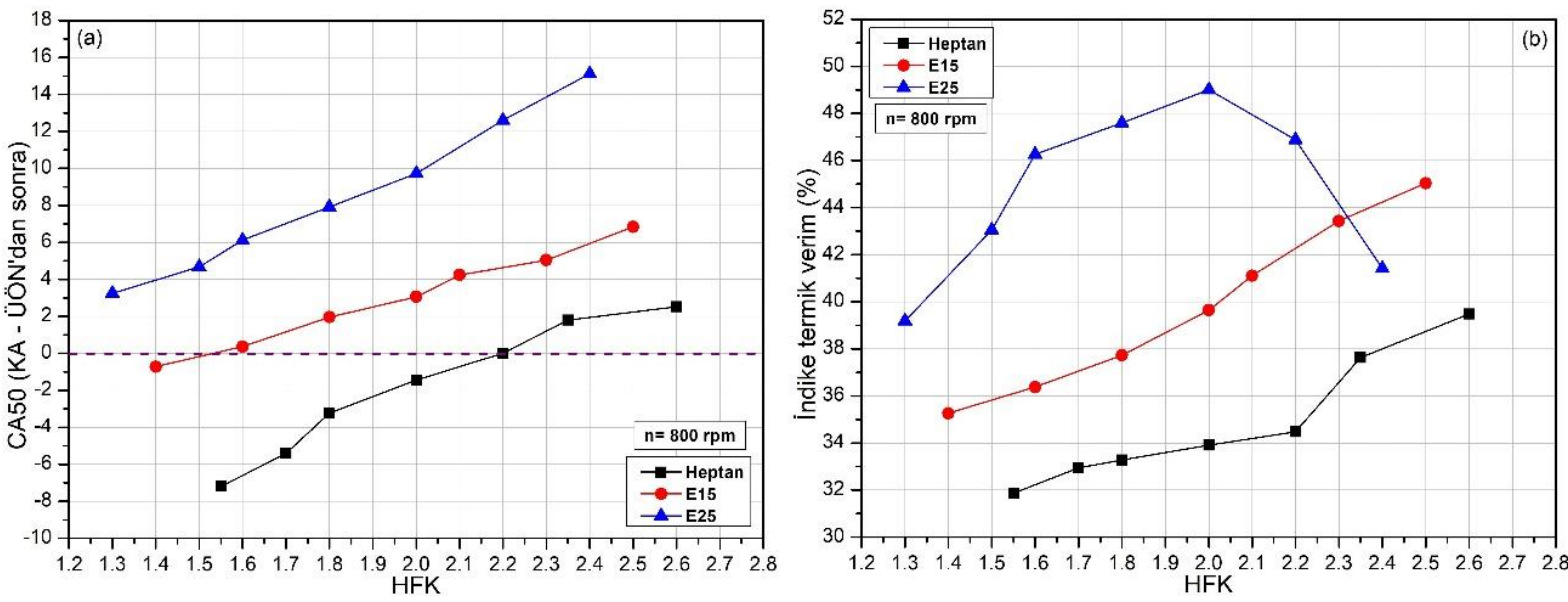

Şekil 4. CA50 ve indike termik verimin HFK'ya bağlı değişimi

HFK'nın artış göstermesi karışımın düşürmektedir. Tüm test yakıtları ile yapılan fakirleşmesini ifade eder. Aşırı fakir karışım şartlarında kendiliğinden başlayan oksidasyon reaskiyonları, silindir içi sıcaklığın daha düşük olmasına neden olur $\mathrm{Bu}$ durum yanmanın yavaşlamasını sağlar. HFK'nın 2 olduğu şartlarda üç test yakıtı karşılaştırmalı olarak incelenirse, heptan yakitına etil alkol ilavesinin HCCI yanma safhasının kontrol altına alınabildiğini görülebilir.

İçten yanmalı motorlarda kümülatif 1S1 dağılımının \%50'sinin gerçekleştiği krank açısının yeri (CA50) indike termik verimi doğrudan etkilemektedir (Heywood, 1988). CA50'nin ÜÖN'dan önce gerçekleşmesi, açığa çıkan 1sı enerjisinin ve yüksek basıncın pistonun aksi yönünde bir kuvvet oluşturmasına ve dolayısıyla piston tarafından yapılacak olan net işin azalmasına sebep olmaktadır. Bu durum indike termik verimi deneysel çalışmada Şekil 4 incelendiğinde pistonun ÜÖN'yı aşarak genişleme zamanının başladığı krank açılarında indike termik verimin maksimum seviyelere ulaştığ görülmektedir. İçten yanmalı motorlarda en yüksek indike termik verim, CA50'nin ÜÖN'dan 7-10 derece sonra gerçekleştiği şartlarda elde edilmektedir (Heywood, 1988). Heptan yakıtı kullanımında bu şartların tüm HFK değerlerinde de elde edilememesi indike termik verimin düşük olmasına neden olmuştur. Heptan yakıtına etil alkol ilavesi yanmayı yavaşlatmış ve gecikmeye almıştır. Buna bağlı olarak E15 yakıtı kullanımında en yüksek indike termik verim, CA50'nin ÜÖN'dan $6,84{ }^{\circ} \mathrm{KA}$ sonra elde edildiği ve HFK'nın 2,5 olduğu şartlarda \%45,03 olarak tespit edilmiştir. E25 yakıtı kullanımında ise en yüksek indike termik verim HFK'nın 2 olduğu şartlarda \%49 olarak gerçekleşmiştir. 
$\mathrm{Bu}$ şartlar altınca CA50'nin yeri ÜÖN'dan $9,72{ }^{\circ} \mathrm{KA}$ sonradır. Daha zengin karışım şartlarında 1Sı dağılımının hızlı gerçekleşmesi vuruntuya sebep olmakta ve indike termik verim azalmaktadır. Daha fakir karışım şartlarında CA50'nin ÜÖN'dan çok sonra gerçekleşmesi indike termik verimin yine azalmasına neden olmuştur.

Şekil 5'de farklı HFK değerlerinde heptan yakıtına etil alkol ilavesinin yanma süresine Birincisi; karışım yakıtlarının heptan yakıtına göre yüksek oktan sayısına sahip olması ve etil alkolün buharlaşma gizli ısısının yüksek olması nedeniyle tutuşma gecikmesine neden olmasıdır. İkicisi ise, karışım yakıtları kullanımında yanmanın ÜÖN'dan sonra başlaması ile yanma sürecinin büyük bir kısmının genişleme zamanına kayarak yanma hızının yavaşlamasıdır. Yüksek motor yüklerinde de (düşük HFK, zengin karışım şartları) E15 ve E25 yakıtı kullanımında yanmanın ÜÖN'dan hemen önce ya da ÜÖN'dan hemen sonra başlaması, yanmanın genişleme zamanında gelişmesine neden olmakta ve yanma süresi heptan yakıtına göre uzamaktadır.

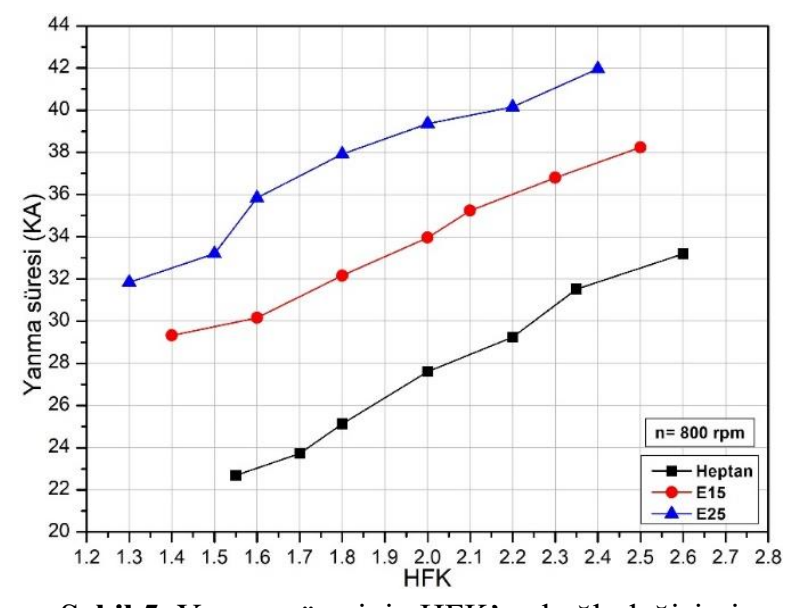

Şekil 5. Yanma süresinin HFK'ya bağlı değişimi

IMEP, bir çevrim boyunca krank açısına bağlı olarak piston üzerine uygulanan basınçların ortalamasinı ifade eden ve motor performansını ifade eden bir parametredir etkisi görülmektedir. Düşük motor yüklerinde (yüksek HFK, fakir karışım şartları altında) karışım yakıtları içerisindeki etil alkol miktarının artışına bağlı olarak açığa çıkan 1sı enerjisi azalmakta (Şekil 2) ve buna bağlı olarak yanma süresi uzamaktadır. Aynı zamanda yanmanın başladığı (CA10) krank açısı ile maksimum 1sı dağılımının elde edildiği krank açısı arasındaki süre de uzamaktadır. Bunun iki temel nedeni vardır.

(Heywood, 1988; Zhao, 2007). Şekil 6'da IMEP'in HFK'ya bağlı değişimi görülmektedir. Tüm test yakıtları için HFK arttıkça IMEP azaldığı görülmektedir. Karışımın fakirleşmesi sonucu silindire alınan enerji ve yanma sonucu açı̆̆a çıkan 1s1 azalmaktadır. Fakir karışımın kendiliğinden tutuşması sonucu oksidasyon reaksiyonları ve alev hızı azalmaktadır. Böylece yanma sonucunda piston üzerine uygulanan basınç da azalır.

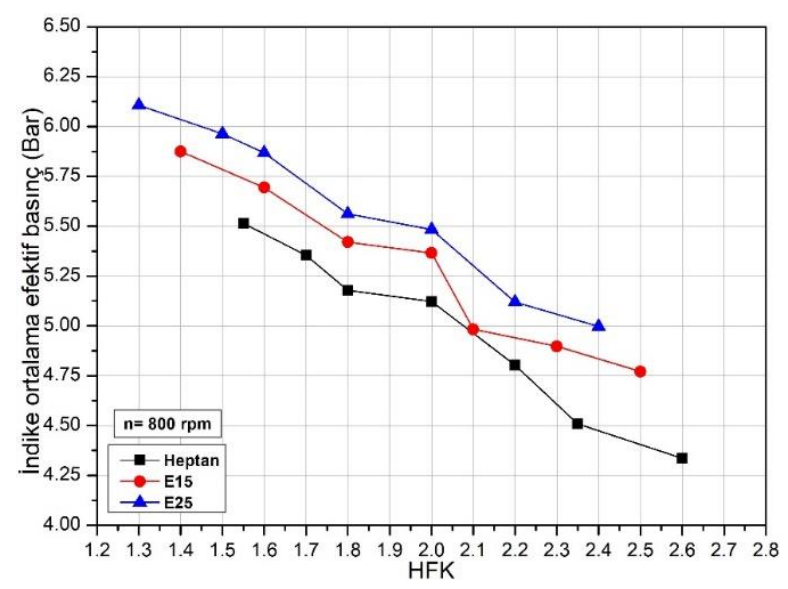

Şekil 6. IMEP'in HFK'ya bağlı değişimi

Bununla birlikte fakir homojen karışımın tutuşması ile yanma odasında daha düşük sıcaklıklar elde edilmekte, silindir duvarlarına yakın lokal bölgelerde gaz sıcaklığı azalmaktadır. Tüm HFK değerlerinde en düşük IMEP heptan yakıtı kullanımı ile elde edildiği görülmektedir. Heptan yakıtı ile homojen karışımın ani olarak tutuşması, yanma odasında basınç dalgalanmalarına ve 
kararsiz bir HCCI yanmasinın gerçekleşmesine neden olmaktadır. Ani ve düzensiz şekilde meydana gelen, kendiliğinden gerçekleşen bu kimyasal reaksiyonlar ile piston üzerine uygulanan basınç azalmaktadır. E25 yakıtı ile yanma daha geç başlamasına rağmen homojen karışımın zengin olması IMEP'i diğer yakıtlara göre artırmıştır. Oksidasyon reaksiyonlarına katılan yakıt moleküllerin fazla olması, açığa çıkan enerjinin artmasına neden olmaktadır. En yüksek IMEP, tüm HFK değerlerinde E25 yakıtı ile elde edilirken vuruntu sınırına yakın yüksek motor yüklerinde maksimum seviyeye ulaşmıştır. HFK'nın 1,3 olduğu şartlarda E25 yakıtının kullanımı ile IMEP 6,1 Bar olarak gerçekleşmiştir.

Şekil 7'de basınç artış oranının HFK'ya bağlı değişimi görülmektedir. Basınç artış oranı, krank açısı başına piston üzerine uygulanan basınc1 ifade etmektedir. İçten yanmalı motorlarda basınç artış oranının $10 \mathrm{Bar} /{ }^{\circ} \mathrm{KA}$ üzeri kararsız çalışma şartları olarak ifade edilmektedir (Zhao, 2007). Tüm test yakıtları için HFK'nın artması ile basınç artış oranı azalmaktadır. Çünkü karışımın fakirleşmesiyle yanma sonucu açığa çıkan basınç da azalmaktadır. Zengin karışım şartlarında yanma odasında birkaç noktadan aynı anda başlayan oksidasyon reaksiyonları silindir içi basıncın çok küçük krank açısı aralıklarında gereğinden çok hızlı bir şekilde artmasına neden olmaktadır. Heptan yakıtı kullanımında zengin karışım bölgesinden HFK'nın 1,8 olduğu şartlara kadar basınç artış oranının $10 \mathrm{bar} /{ }^{\circ} \mathrm{KA}$ değerini oldukça aştığ 1 ve çok ciddi vuruntunun meydana geldiği görülmektedir. Ancak E15 ve E25 yakıt1 kullanımında daha zengin karışım bölgelerinde dahi daha stabil HCCI yanmasının gerçekleştiği, vuruntu sınırından uzaklaşıldığı görülmektedir. HCCI yanmasında yüksek oktanlı alternatif yakıtların kullanımı, vuruntu oluşumunu azaltmakta ve daha kararlı HCCI çalışma bölgeleri sağlamaktadır.

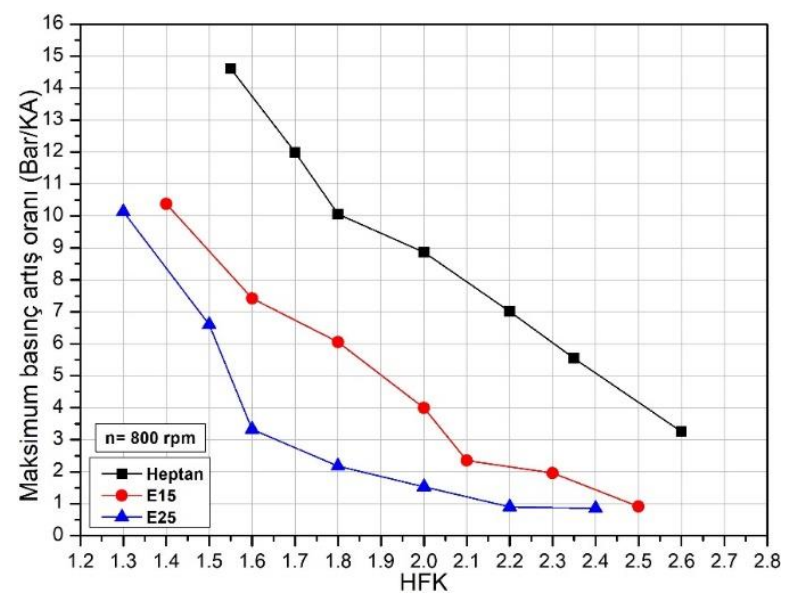

Şekil 7. Basınç artış oranının HFK'ya bağlı değişimi

HCCI motorlarda yanma sonu sıcaklıkları CO emisyonunu önemli ölçüde etkilemektedir. Vuruntu sınırına yakın HFK'nın düşük olduğu şartlarda, erken yanma başlangıcı ile birlikte CO emisyonu düşük seviyelerde açığa çıkmaktadır.

Ancak tekleme sinırına yakın HFK'nın yüksek olduğu çalışma şartlarında gecikmiş yanma CO emisyonunun artmasına neden olmaktadır. Şekil 8, HFK'ya bağlı CO emisyonunun değişimini göstermektedir. Tüm test yakıtları için fakir karışım şartlarında CO emisyonunun oldukça yüksek olduğu görülmektedir. Karışımın zenginleşmesi ile yanma sonu sıcaklıkları artmakta ve CO emisyonları azalmaktadır. Karışım yakıtlarına ait yanma sonu sıcaklıklarının heptan yakıtına göre daha düşük olması $\mathrm{CO}$ emisyonlarının da artış göstermesine neden olmuştur. HFK'nın 1,8 olduğu şartlardan daha fakir karışım şartlarına doğru gidildikçe E15 ve E25 yakıtları kullanımı ile CO emisyonları oldukça fazla artış göstermiştir. 


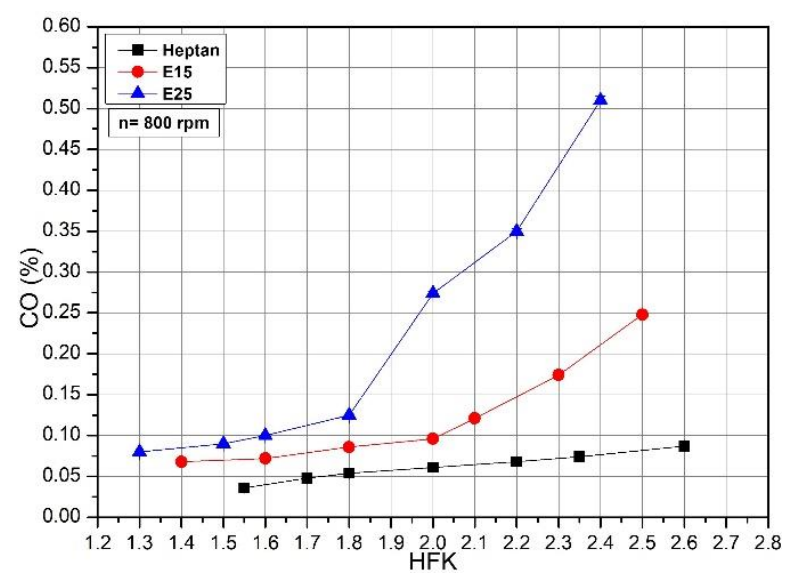

Şekil 8. CO emisyonlarının HFK'ya bağlı değişimi

HCCI motorlarda yanma, düşük sıcaklıklarda gerçekleşmektedir. $\mathrm{Bu}$ nedenle $\mathrm{HCCI}$ motorlar yüksek HC emisyonlarına neden olmaktadır. Özellikle silindir duvarlarına yakın bölgelerde gerçekleşen 1sı kayıpları nedeniyle silindir içi gaz sıcaklıkları azalmaktadır. $\mathrm{Bu}$ nedenle yanma bu bölgelerde sönebilir ya da hiç gerçekleşmeyebilir. Homojen karışımın yanması esnasında hacim genişlerse silindir içi gaz sıcaklıkları hızlı bir şekilde azalacaktır. Özellikle yanma sonunda sıcaklığın çok düşük olması oksidasyon reaksiyonlarını önemli ölçüde bozmakta ve çok fazla HC emisyonu meydana gelmesine neden olur. Şekil 9'da HFK'ya bağlı olarak HC emisyonlarının değişimi görülmektedir. Heptan yakıtına göre E15 yakıtı kullanımında HC emisyonları bir miktar artış gösterirken E25 yakıtı ile ortalama \%50'den fazla artış göstermektedir. Şekil 3 incelendiğinde yanmanın ÜÖN'dan önce ya da ÜÖN'ya oldukça yakın başladığı çalışma şartları HC emisyonlarını olumlu yönde etkilemektedir. Ancak yanmanın uzun sürdüğü ve gecikmeye alındığı fakir karışım şartları, tüm test yakıtları kullanımında $\mathrm{HC}$ emisyonlarının artmasına neden olmuştur. Tüm HFK değerlerinde en düşük HC emisyonları heptan yakıtı ile elde edilirken karışım yakıtlarındaki etil alkol miktarına bağlı olarak HC emisyonları artış göstermiştir.

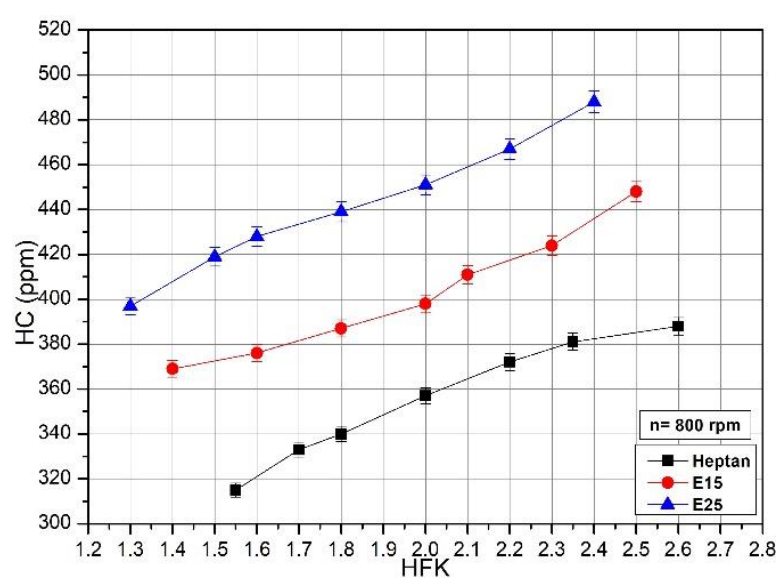

Şekil 9. HC emisyonlarının HFK' ya bağlı değişsimi

\section{Sonuçlar}

$\mathrm{Bu}$ çalışmada heptan yakıtına etil alkol ilavesinin HCCI çalışma şartlarına etkisi deneysel olarak incelenmiştir. Tek silindirli, port enjeksiyonlu bir HCCI motorda, $60{ }^{\circ} \mathrm{C}$ emme havası giriş sı sıklığında gerçekleştirilen deneylerde farklı motor yüklerinde (HFK'nın değişimi) ve $800 \mathrm{rpm}$ motor hizında yanma, performans ve $\mathrm{CO}$ ile HC emisyonlarının değişimi rapor haline getirilmiştir. Heptan yakıtına etil alkol ilavesi çalışma aralığının zengin karışım bölgelerine kaymasına neden olmuştur. Ancak karışım yakıtlarındaki etil alkol miktarına bağlı olarak yanma gecikmeye alınmıştır. Bununla birlikte etil alkolün zor buharlaşması, silindir içi gaz sıcaklıklarını düşürmüş, oksidasyon reaksiyonlarını yavaşlatarak yanma süresinin uzamasına neden olmuştur. Bunun bir diğer temel nedeni ise karışım yakıtlarında yanmanın büyük bir kısmının genişleme zamanına kaymasıdır. Heptan yakıtına etil alkol ilavesi yanma başlangıcının kontrol edilmesini sağlamış ve yanmanın daha uzun krank açılarında gerçekleşmesini sağlayarak basınç artış oranının azaltılmasına olanak tanımıştır. Heptan yakıtına etil alkol ilavesi karışım yakıtlarının ısıl değerini düşürmesine rağmen, uygun HFK değerlerinde yanma sürecinin kontrol altına alınmasının etkisiyle indike termik verimin artmasını sağlamıştır. Aynı zamanda IMEP karışım yakıtları ile artış 
göstermiştir. $\mathrm{CO}$ ve $\mathrm{HC}$ emisyonları yanma sonu sicaklıklarından doğrudan etkilenmektedir ve yakıt karışımında etil alkol oranı arttıkça $\mathrm{CO}$ ve $\mathrm{HC}$ emisyonları artmaktadır (Gharehghani, 2019). Hava fazlalığının 1,8 'den daha fazla olduğu fakir karışımlarda; E15 test yakıtı kullanımı ile CO ve $\mathrm{HC}$ emisyonlarında sirasiyla ortalama olarak $\% 85$ ve $\% 11$, E25 test yakitı kullanımında ise $\mathrm{CO}$ ve $\mathrm{HC}$ emisyonlarında sirasiyla ortalama olarak $\% 300$ ve $\% 27$ kötüleşme gözlenmişstir.

\section{Kaynaklar}

Blomberg, C. K., Wright, Y. M. ve Boulouchos, K. 2018. "A phenomenological HCCI combustion model in $0 \mathrm{D}$ and 3DCFD", Fuel, 226, 365-380.

Christensen, M., Johansson, B. ve Einewall, P. 1997. "Homogeneous charge compression ignition (HCCI) using isooctane, ethanol and natural gas-a comparison with spark ignition operation", SAE Technical Paper, No. 972874.

Cinar, C., Uyumaz, A., Solmaz, H., Sahin, F., Polat, S. ve Yilmaz, E. 2015. "Effects of intake air temperature on combustion, performance and emission characteristics of a HCCI engine fueled with the blends of $20 \% \mathrm{n}$ heptane and $80 \%$ isooctane fuels", Fuel Processing Technology, 130, 275-281.

Curran, H. J., Pitz, W. J., Westbrook, C. K., Callahan, G. V. ve Dryer, F. L. 1998. "Oxidation of automotive primary reference fuels at elevated pressures", Symposium (International) on Combustion, 27(1), 379387.

Gharehghani, A. 2019. "Load limits of an HCCI engine fueled with natural gas, ethanol, and methanol", Fuel, 239, 1001-1014.

Heywood, J. B. 1988. "Internal combustion engine fundamentals", McGraw Hill.
Huang, H. ve Su, W. 2005. "A new reduced chemical kinetic model for autoignition and oxidation of lean n-heptane/air mixtures in HCCI engines", SAE Technical Paper, No. 2005-01-0118.

Kozlov, V. E., Titova, N. S. ve Chechet, I. V. 2018. "Modeling study of hydrogen or syngas addition on combustion and emission characteristics of HCCI engine operating on iso-octane", Fuel, 221, 61-71.

Li, R., Liu, Z., Han, Y., Tan, M., Xu, Y., Tian, J., Yan, J., Meng, X., Wei, M., Hu, S., Chong, D. ve Li, L. 2018. "Experimental study of the combustion and emission characteristics of ethanol, diesel-gasoline, n-heptane-isooctane, n-heptane-ethanol and decane-ethanol in a constant volume vessel", Fuel, 232, 233250.

Li, Y., Zhao, H. ve Brouzos, N. 2008. "CAI combustion with methanol and ethanol in an air-assisted direct injection SI engine", SAE Technical Paper, No. 2008-01-1673.

Lü, X., Hou, Y., Zu, L. ve Huang, Z. 2006. "Experimental study on the auto-ignition and combustion characteristics in the homogeneous charge compression ignition ( $\mathrm{HCCI}$ ) combustion operation with ethanol/nheptane blend fuels by port injection", Fuel, 85(17-18), 2622-2631.

Maurya, R. K. ve Agarwal, A. K. 2014. "Experimental investigations of performance, combustion and emission characteristics of ethanol and methanol fueled HCCI engine", Fuel Processing Technology, 126, 30-48.

Noh, H. K. ve No, S. Y. 2017. "Effect of bioethanol on combustion and emissions in advanced CI engines: HCCI, PPC and GCI mode-A review", Applied Energy, 208, 782802.

Oakley, A., Zhao, H., Ladommatos, N. ve Ma, T. 2001. "Dilution effects on the controlled 
auto-ignition (CAI) combustion of hydrocarbon and alcohol fuels", SAE Transactions, 2086-2099.

Ogawa, H., Miyamoto, N., Kaneko, N. ve Ando, H. 2003. "Combustion control and operating range expansion with direct injection of reaction suppressors in a premixed DME HCCI engine", SAE Technical Paper, No. 2003-01-0746.

Peng, Z., Zhao, H. ve Ladommatos, N. 2003. "Effects of air/fuel ratios and EGR rates on HCCI combustion of n-heptane, a diesel type fuel", SAE Technical Paper, No. 2003-010747.

Polat, S. 2016. “An experimental study on combustion, engine performance and exhaust emissions in a HCCI engine fuelled with diethyl ether-ethanol fuel blends", Fuel Processing Technology, 143, 140-150.

Poulopoulos, S. G., Samaras, D. P. ve Philippopoulos, C. J. 2001. "Regulated and unregulated emissions from an internal combustion engine operating on ethanolcontaining fuels", Atmospheric Environment, 35(26), 4399-4406.

Saisirirat, P., Togbé, C., Chanchaona, S., Foucher, F., Mounaim-Rousselle, C. ve Dagaut, P. 2011. "Auto-ignition and combustion characteristics in HCCI and JSR using 1-butanol/n-heptane and ethanol/nheptane blends", Proceedings of the Combustion Institute, 33(2), 3007-3014.

Shibata, G., Oyama, K., Urushihara, T. ve Nakano, T. 2005. "Correlation of low temperature heat release with fuel composition and HCCI engine combustion", SAE Technical Paper, No. 2005-01-0138.

Shudo, T., Shima, Y. ve Fujii, T. 2009. "Production of dimethyl ether and hydrogen by methanol reforming for an HCCI engine system with waste heat recovery-Continuous control of fuel ignitability and utilization of exhaust gas heat", International Journal of Hydrogen Energy, 34(18), 7638-7647.

Tongroon, M. ve Zhao, H. 2010. "Combustion characteristics of CAI combustion with alcohol fuels", SAE Technical Paper, No. 2010-01-0843.

Uyumaz, A. 2015. “An experimental investigation into combustion and performance characteristics of an HCCI gasoline engine fueled with $n$-heptane, isopropanol and n-butanol fuel blends at different inlet air temperatures", Energy Conversion and Management, 98, 199-207.

Xie, H., Wei, Z., He, B. ve Zhao, H. 2006. "Comparison of HCCI combustion respectively fueled with gasoline, ethanol and methanol through the trapped residual gas strategy", SAE Technical Paper, No. 2006-010635.

Yao, M., Zheng, Z. ve Liu, H. 2009. "Progress and recent trends in homogeneous charge compression ignition (HCCI) engines", Progress in Energy and Combustion Science, 35(5), 398-437.

Zhang, C. ve Wu, H. 2016. "Combustion characteristics and performance of a methanol fueled homogenous charge compression ignition (HCCI) engine", Journal of the Energy Institute, 89(3), 346-353.

Zhang, C. ve Wu, H. 2012. "The simulation based on CHEMKIN for homogeneous charge compression ignition combustion with onboard fuel reformation in the chamber", International Journal of Hydrogen Energy, 37(5), 4467-4475.

Zhao, H. 2007. "HCCI and CAI engines for the automotive industry", Woodhead Publishing Limited, Cambridge.

Zhao, F., Asmus, T. N., Assanis, D. N., Dec, J. E., Eng, J. A. ve Najt, P. M. 2003. 
"Homogeneous charge compression ignition homogeneous charge combustion of n(HCCI) engines", SAE Technical Paper, No. heptane”, SAE Technical Paper, No. 2004-01PT-94. 1905.

Zheng, J., Miller, D. L., Cernansky, N. P., Liu, D., Zhao, X. ve Zhang, M. 2004. "Some observations on the effects of EGR, oxygen concentration, and engine speed on the 